\title{
Propranolol pharmacokinetics during the menstrual cycle
}

\author{
I. Abdu-Aguye, D. Dunlop, P. Patel and P. Turner \\ Department of Clinical Pharmacology, St Bartholomew's Hospital, London EC1A 7BE, UK.
}

\begin{abstract}
Summary: The pharmacokinetics of propranolol during menstruation and in the mid menstrual cycle have been studied in nine young women taking a single $80 \mathrm{mg}$ tablet on each occasion. There were wide between-individual differences in the serum concentration at any given time (4-5 fold at peak concentrations) but the serum concentration time curves within individuals showed only mild variations. The differences between the average pharmacokinetic parameter estimates for the group did not differ significantly between the two periods of study.
\end{abstract}

\section{Introduction}

Propranolol has an established role in the prophylaxis of migraine, but its mechanism of action in this condition remains uncertain (Weerasuriya et al., 1982). The varying dosages required for effective control of attack in different patients indicates that there is unlikely to be a simple relationship between serum propranolol concentration and its effectiveness. Cortelli et al. (1985) have indeed shown that there is no relationship between plasma levels and relief of headaches. However, Gengo et al. (1984) found that regular premenstrual failure of migraine prophylaxis with this agent in an otherwise well controlled patient was associated with lowered steady-state serum level. Further studies in the same patient revealed that following the same oral dose, serum propranolol concentrations were markedly lower on her first menstrual day compared to those on the sixteenth day.

In order to confirm that the serum propranolol concentrations may be influenced by the menstrual cycle we undertook a study in a group of healthy young volunteers. We also studied the influence of the menstrual cycle on the average pharmacokinetic parameter estimates of the drug.

\section{Patients and methods}

We studied nine volunteers (average age 24 years, range 18-43 years). Local ethical committee approval was obtained and each volunteer gave informed consent. There was no evidence of respiratory or cardiovascular disease in any of the volunteers and none was taking oral contraceptive pills. Each volunteer attended for study twice, first within 24 hours of

Correspondence: Professor P. Turner M.D., B.Sc., F.R.C.P. Accepted: 17 June 1986 beginning menstruation and secondly 16 days later.

After an overnight fast, an $80 \mathrm{mg}$ propranolol tablet was given by mouth and $10 \mathrm{ml}$ blood samples were taken from an antecubital vein through an indwelling catheter at $0,0.5,1,1.5,2,2.5,3,4,5,6,7,8$ and 10 hours for estimation of serum propranolol levels. The blood was allowed to clot and centrifuged to separate the serum. Samples were stored at $-20^{\circ} \mathrm{C}$ until analysed. During the study, volunteers were allowed only a low protein breakfast 2 hours, and low protein lunch 5 hours, after taking the tablet.

Measurement of propranolol concentrations was carried out by a modified spectrofluorimetric method as described by Heagerty et al. (1981) using a PerkinElmer LS-5 luminescence spectrometer. Three $\mathrm{ml}$ rather than $1.5 \mathrm{ml}$ of $0.01 \mathrm{~N}$ acid was used because of the larger sized cuvette available. Quality controls using 10,30 and $80 \mathrm{ng} / \mathrm{ml}$ of propranolol in blank serum were measured after every ten volunteer samples.

The serum concentrations of propranolol obtained for each volunteer on the two separate occasions were individually submitted to pharmacokinetic analysis by a computer program, STRIPE, as described by Johnston \& Woollard (1983).

The means of the data obtained for a particular parameter obtained in all the volunteers were computed and compared by means of Student's $t$ test for paired data on a Hewlett Packard HP-85 computer.

\section{Results}

The means of the quality control samples were 10.9 , 29.4 and $79.8 \mathrm{ng} / \mathrm{ml}$ and their coefficients of variation were $8,6.5$ and $8 \%$ respectively. Figure 1 shows the mean serum propranolol concentration time curves

(C) The Fellowship of Postgraduate Medicine, 1986 


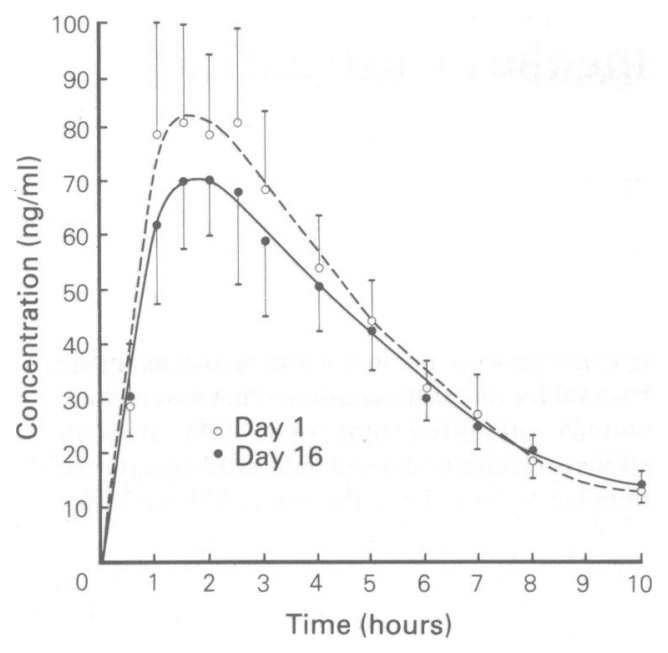

Figure 1 Serum propranolol levels (mean \pm s.e.m.) in 9 healthy women following $80 \mathrm{mg}$ propranolol orally on day $1\left(\mathrm{O}_{--\mathrm{O})}\right.$ and day $16(\mathrm{O})$ of the menstrual cycle.

over the 10 hours of measurement for the two days of study. On a semi-log plot the data fit a one compartment model. The estimates varied from day 1 to day 16 but there was no consistent pattern. Table I shows the average of the estimated pharmacokinetic parameters and the results of statistical analysis. As can be seen from the $P$ values, the differences between the means do not reach a level of statistical significance on any of the parameters.

\section{Discussion}

The influence of the menstrual cycle on drug metabol- $\frac{\varrho}{c}$ ism has not been the subject of much study. However, Reister et al. (1980) showed that the menstrual cycle had little or no effect on the mean antipyrine salivaryo half life, mean metabolic clearance rate or apparent volume of distribution. They found individual varia- $\frac{\bar{p}}{7}$ tion in kinetic parameters from day to day but noted $\stackrel{\mathbb{Q}}{\Omega}$ that there was no consistent pattern in this variation.

Propranolol pharmacokinetics are influenced by several factors. Shand et al. (1970) showed that the half life was shorter following an intravenous dose $\overrightarrow{\vec{\omega}}$ when compared to an oral dose. The same result was $\stackrel{\omega}{\sigma}$ found if the oral dose was taken on an empty stomach. Castleden et al. (1975) found that given the same oral 3 . dose, substantially greater plasma levels were attained os in elderly subjects compared with younger ones. Heagerty et al. (1981) showed that concurrent $\stackrel{\oplus}{\oplus}$ cimetidine therapy led to both a higher blood propran- $\overrightarrow{ }$ olol concentration and relative bioavailability. Patel et $\stackrel{\&}{\mathrm{c}}$ al. (1983) demonstrated that the area under the curve for propranolol administered per vaginam was sig- $\supset$ nificantly greater than that after oral administration. $\vec{\square}$ In addition, Walle et al. (1985) have shown that higher $\stackrel{\mathbb{D}}{\varnothing}$ serum levels occurred for a given dose in women than in men, in Caucasians than in Blacks and in non- $\frac{\vec{O}}{0}$ smokers than smokers.

The serum propranolol levels obtained in this grou $\overrightarrow{0}$ of volunteers are similar to those described by Salem McDevitt (1984) and notwithstanding the problen associated with this type of study (Martin et al., 1984), we believe that these results do not indicate that the pharmacokinetics of propranolol are significantly different between these two days in our volunteers.

Table I Mean ( \pm s.e.m.) estimated pharmacokinetic parameters of oral propranolol in 9 healthy volunteers on the 1st and 16 th day of the menstrual cycle.

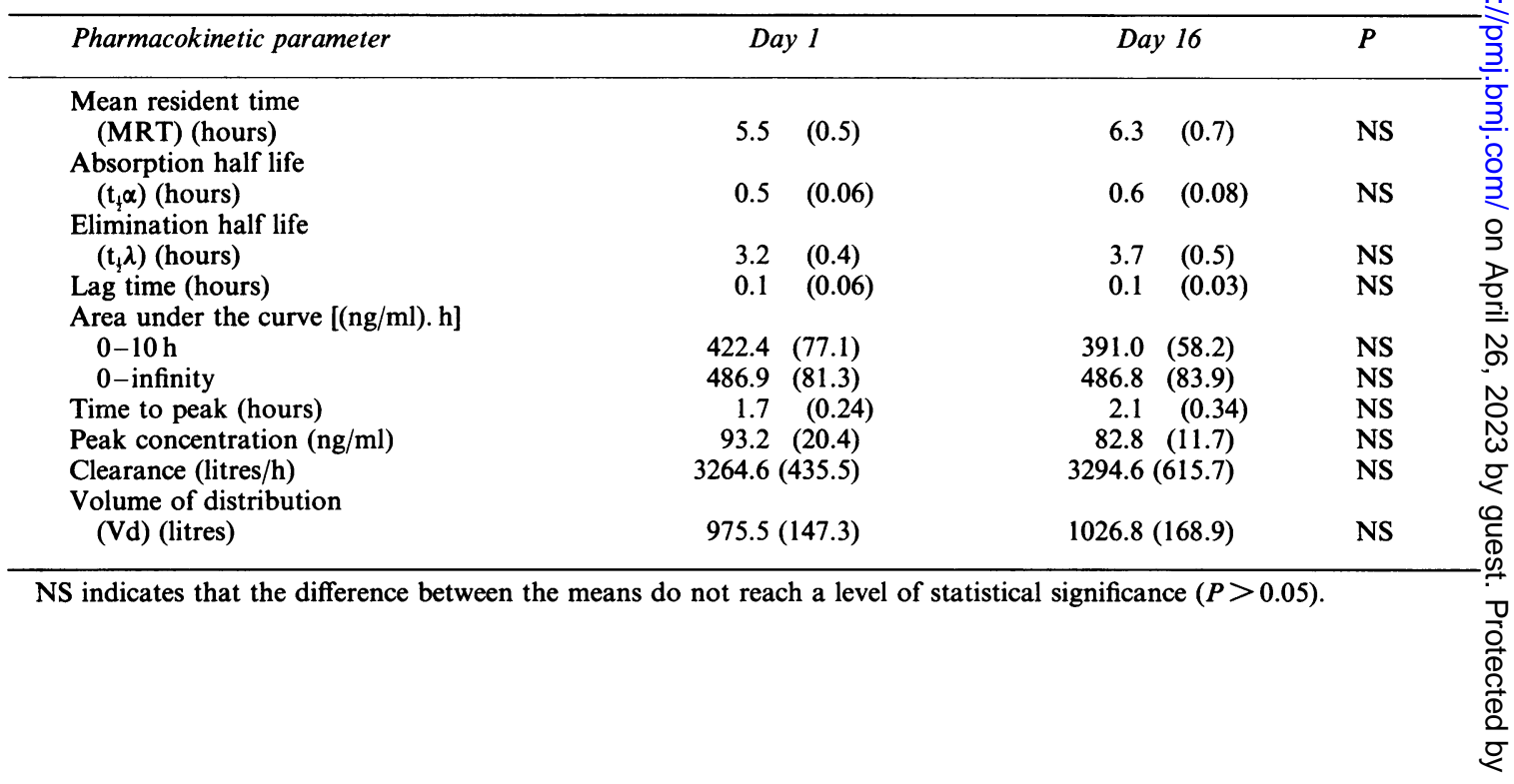


It is possible that there might be a relationship between migraine and the phenomenon reported by Gengo et al. (1984) and we suggest that the study should be repeated in a suitable group of migrainous women whose attacks are related to the menstrual flow.

\section{References}

CASTLEDEN, C.M., KAYE, C.M.\& PARSONS, R.L. (1975). The effect of age on plasma levels of propranolol and practolol in man. British Journal of Clinical Pharmacology, 2, 303.

CORTELLI, P., SACQUEGNA, T., ALBANI, F., BALDRATI, A., D'ALESSANDRO, R., BARUZZI, A. \& LUGARESI, E. (1985). Propranolol plasma levels and relief of migraine: relationship between plasma propranolol and 4-hydroxy-propranolol concentrations and clinical effects. Archives of Neurology, 42, 42.

GENGO, F.M., FAGAN, S.C., KINKEL, W.R. \& MCHUGH, W.B. (1984). Serum concentrations of propranolol and migraine prophylaxis. Archives of Neurology, 41, 1306.

HEAGERTY, A.M., DONOVAN, M.A., CASTLEDEN, C.M., POHL, J.F., PATEL, L. \& HEDGES, A. (1981). Influence of cimetidine on pharmacokinetics of propranolol. British Medical Journal, $282,1917$.

JOHNSTON, A. \& WOOLLARD, R.C. (1983). STRIPE: an interactive computer program for the analysis of drug pharmacokinetics. Journal of Pharmacological Methods, 9, 193.

MARTIN, E., MOLL, W., SCHMID, P. \& DETTLI, L. (1984). Problems and pitfalls in estimating average pharmacokinetic parameters. European Journal of Clinical Pharmacology, 26, 595.

\section{Acknowledgements}

We thank the young women who volunteered to take part in this study. I.A-A is supported by The Association of Commonwealth Universities under its Medical Fellowship Award.

PATEL, L.G., WARRINGTON, S.J. \& PEARSON, R.M. (1983). Propranolol concentrations in plasma after insertion into the vagina. British Medical Journal, 287, 1247.

REISTER, E.F., PANTUCK, E.J., PANTUCK, C.B., PASSANANTI, G.T., VESSEL, E.S. \& CONNEY, A.H. (1980). Antipyrine metabolism during the menstrual cycle. Clinical Pharmacology and Therapeutics, 28, 384.

SALEM, S.A.M. \& MCDEVITT, D.G. (1984). Central effects of single oral doses of propranolol in man. British Journal of Clinical Pharmacology, 17, 31.

SHAND, D.G., NUCKOLLS, E.M. \& OATES, J.A. (1970). Plasma propranolol levels in adults with observations in four children. Clinical Pharmacology and Therapeutics, 11, 112.

WALLE, T., BYINGTON, R.P., FURBERG, C.D., MCINTYRE, K.M. \& VOKONAS, P.S. (1985). Biologic determinants of propranolol disposition: results from 1308 patients in the beta-blocker heart attack trial. Clinical Pharmacology and Therapeutics, 38, 509.

WEERASURIYA, K., PATEL, L. \& TURNER, P. (1982). Beta adrenoceptor blockade and migraine. Cephalalgia, $2,33$. 